Case Report

\title{
A Case of Acute Autoimmune Hepatitis Superimposed on Chronic Hepatitis B Infection
}

\author{
Vanessa Sostre, ${ }^{1}$ Hiren G. Patel $\complement_{0},{ }^{2}$ Abdalla Mohamed, ${ }^{1}$ and Ariy Volfson ${ }^{2}$ \\ ${ }^{1}$ Department of Internal Medicine, St. Joseph's University Medical Center, Paterson, NJ, USA \\ ${ }^{2}$ Department of Gastroenterology and Hepatology, St. Joseph's University Medical Center, Paterson, NJ, USA
}

Correspondence should be addressed to Hiren G. Patel; hiren727@gmail.com

Received 2 January 2018; Revised 18 February 2018; Accepted 28 February 2018; Published 1 April 2018

Academic Editor: Olga I. Giouleme

Copyright (c) 2018 Vanessa Sostre et al. This is an open access article distributed under the Creative Commons Attribution License, which permits unrestricted use, distribution, and reproduction in any medium, provided the original work is properly cited.

\begin{abstract}
Autoimmune hepatitis has been associated with chronic HCV infection, but there are only few cases reported of HBV infection as a possible trigger. We present a case of a young male who was diagnosed with acute autoimmune hepatitis superimposed on existent chronic HBV infection. A 30-year-old Hispanic male with no past medical history presented to the hospital with complaints of few days of generalized weakness. Laboratory findings were significant for elevated liver enzymes: AST, 1164 U/L; ALT, 1461 U/L; total bilirubin, $2 \mathrm{MG} / \mathrm{DL}$; and alkaline phosphatase, $75 \mathrm{IU} / \mathrm{L}$. Extensive workup was done to find the etiology for elevated liver enzymes. Only blood work that came back positive was for chronic HBV infection and elevated immunoglobulin G (IgG) level $1937 \mathrm{mg} / \mathrm{dL}$. HBV viral load was 42,900,000 IU/mL. The patient was started on tenofovir $300 \mathrm{mg}$ daily. Liver biopsy was done which was consistent with autoimmune hepatitis. Prednisone $60 \mathrm{mg}$ daily was started. Six months later, blood work showed completely normal liver enzymes and total IgG. Hepatotropic viruses have been proposed as triggering factors for several autoimmune diseases. There are theories suggesting that similarity in viral epitope and self-proteins expression on liver cells' surface causes a cross-reactive immunologic response and possible viral-induced autoimmune hepatitis.
\end{abstract}

\section{Introduction}

Autoimmune hepatitis (AIH) is an uncommon chronic liver inflammation with an unclear etiology [1]. Like most of the autoimmune diseases, it is predominant in females with a prevalence of less than $0.02 \%$ [1]. "Lupoid hepatitis," as it was called in the past, has been associated with other hepatic diseases such as drug-induced liver injury, primary biliary cholangitis, primary sclerosing cholangitis, and viral hepatitis, specifically hepatitis $C$ virus [2]. There are few cases reported for hepatitis B virus (HBV) as a possible trigger of this rare disease [3-7]. We present a case of a young male who was diagnosed with acute AIH superimposed on underlying chronic HBV infection.

\section{Case Report}

A 30-year-old Hispanic male with no past medical history presented to the hospital with a complaint of generalized weakness for a few days. The patient denied abdominal pain, nausea, vomiting, pruritus, illicit drug use, skin tattoos, blood transfusions, alcohol abuse, acetaminophen use, recent travel, or multiple sexual partners. He denied any history of liver disease. Physical exam was completely normal. Laboratory findings were significant for elevated liver enzymes: AST, $1164 \mathrm{U} / \mathrm{L} ; \mathrm{ALT}, 1461 \mathrm{U} / \mathrm{L}$; total bilirubin, $2 \mathrm{MG} / \mathrm{DL}$; alkaline phosphatase, 75 IU/L; PT/INR, 14.5/1.1. An extensive workup was done to find the etiology of elevated liver enzymes. Only blood work that came back positive was for chronic Hep B infection (positive for $\mathrm{HBsAg}$, $\mathrm{HBeAg}$, and $\mathrm{HBcIgG}$; negative for $\mathrm{HBs} \mathrm{Ab}$ and $\mathrm{HBcIgM}$ ) and elevated total immunoglobulin G (IgG) level $1937 \mathrm{mg} / \mathrm{dL}$. The rest of the workup including acetaminophen level, hepatitis C antibody, HAV Ab IgM, hepatitis D Ab, EBV DNA, HSV DNA, CMV DNA, and hepatitis $\mathrm{E} A \mathrm{~b}$ came back negative. The autoantibodies for AIH including ANA, ASMA, and anti-LKM also came back negative. Ultrasound of the liver was unremarkable. Hepatitis B viral load was $42,900,000 \mathrm{IU} / \mathrm{mL}$. The patient was started on tenofovir $300 \mathrm{mg}$ daily. Liver biopsy was done, which demonstrated lymphoplasmacytic infiltrate with prominent 
TABLE 1: Trend of laboratory results.

\begin{tabular}{|c|c|c|c|c|c|c|}
\hline Labs & $\begin{array}{c}\text { Labs on } \\
\text { presentation }\end{array}$ & $\begin{array}{c}\text { Day } 1 \text { of } \\
\text { prednisone }\end{array}$ & $\begin{array}{l}\text { Day } 2 \text { of } \\
\text { prednisone }\end{array}$ & $\begin{array}{c}\text { Day } 3 \text { of } \\
\text { prednisone }\end{array}$ & $\begin{array}{c}\text { Day } 10 \text { of } \\
\text { prednisone, } \\
\text { one-week } \\
\text { follow-up }\end{array}$ & $\begin{array}{l}\text { 6-month } \\
\text { follow-up }\end{array}$ \\
\hline AST (U/L) & 1164 & 1258 & 855 & 562 & 155 & 81 \\
\hline $\operatorname{ALT}(\mathrm{U} / \mathrm{L})$ & 1461 & 2010 & 1676 & 1265 & 430 & 39 \\
\hline $\operatorname{ALP}(\mathrm{U} / \mathrm{L})$ & 75 & 98 & 87 & 94 & 121 & 63 \\
\hline T. bilirubin (MG/DL) & 2 & 4.6 & 4.7 & 4.1 & 3.4 & 0.9 \\
\hline Total IgG (MG/DL) & 1937 & NA & 1632 & NA & 1427 & 1192 \\
\hline PT (SEC) & 14.5 & 19.1 & 19.1 & 17.2 & 14.3 & 13.8 \\
\hline INR & 1.1 & 1.6 & 1.6 & 1.4 & 1.1 & 1 \\
\hline HBV (IU/MI) & 42900000 & & & & 2699 & $\begin{array}{l}\text { HBV viral load } \\
\text { undetected }\end{array}$ \\
\hline
\end{tabular}

plasma cells in the portal tracts with marked interface activity and multiple areas of hepatic necrosis consistent with autoimmune hepatitis (Figures 1 and 2). Three days after starting tenofovir, no significant improvement in liver enzymes was seen, so prednisone $60 \mathrm{mg}$ once a day was started. 48 hours after starting prednisone, liver enzymes level dropped significantly (Table 1). The patient was discharged home on tenofovir $300 \mathrm{mg}$ daily and prednisone $60 \mathrm{mg}$ daily. One week after discharge, the patient was seen in the outpatient clinic and at that time transaminases and IgG level were significantly trended down (Table 1). The patient was given a tapering dose of prednisone $40 \mathrm{mg} /$ day on week 2 and $30 \mathrm{mg} /$ day on weeks 3 and 4 and was kept on $20 \mathrm{mg} /$ day as a maintenance dose. The patient was on tenofovir and maintenance dose of prednisone at 6-month follow-up. Blood work showed completely normal liver enzymes and total $\operatorname{Ig} G$ with undetected HBV viral load (Table 1). Autoantibodies for $\mathrm{AIH}$ were still negative in the blood work which was done at 6-month follow-up.

\section{Discussion}

Hepatotropic viruses have been proposed as triggering factors for several autoimmune diseases; for example, chronic HCV infection has been associated with the development of $\mathrm{AIH}$ [2]. Pathogenesis of development of AIH in patients with chronic HBV infection is not well understood. There are theories suggesting that the target site for an immunologic response might be related to viral antigens being expressed on liver cells' surface [3]. Molecular mimicry defined as similarity in viral epitope and self-proteins causes a crossreactive immunologic response that could cause the development of viral-induced autoimmune hepatitis $[2,4,8]$. When there is no active HBV replication, low suppressor T-cell activity was demonstrated in cases with AIH. This is not completely proven, but previous studies suggested that this process allows B-cells to proliferate and develop autoantibodies to liver cells causing this autoimmune phenomenon [3]. The stimulation of antigen presenting cells or expression of major histocompatibility complex on the cell membranes by inflammatory cytokines allowed the

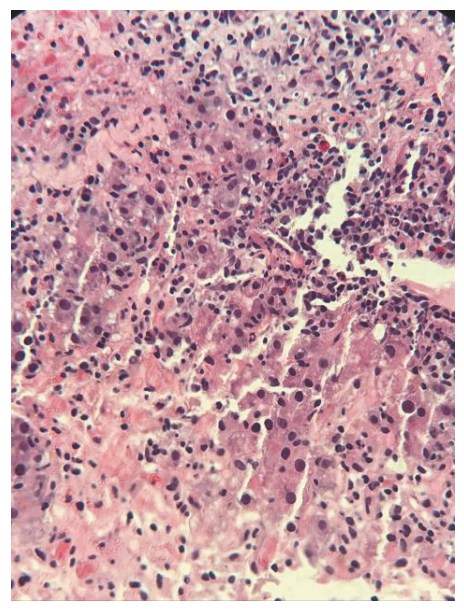

FIgURE 1: H\&E stain of liver biopsy at high power. Liver Biopsy Pathology Report. Prominent lymphoplasmacytic infiltrate in the portal tracts with marked interface activity and multiple areas of hepatic necrosis. In some foci, plasma cells are particularly prominent.

risk of autoreactivity during the response to viral infection [9].

In order to diagnose $\mathrm{AIH}$, it is important to exclude other causes of the chronic liver disease first. Patients with AIH usually have elevated liver enzymes and IgG. High levels of IgG have been seen in up to $85 \%$ of patients [2]. There are three types of AIH based on serologic findings. AIH type 1 is the most common with elevated anti-smooth muscle antibodies (SMA) and antinuclear antibodies (ANA). Elevated levels of anti-liver kidney microsome 1 (anti-LKM-1) and anti-liver cytosol type 1 antibody (anti-LC-1) are present in AIH type 2. Two markers for AIH type 3 are anti-soluble liver antigen (anti-SLA) and anti-liver-pancreas (anti-LP). The presence of these autoantibodies is important but not pathognomonic for the diagnosis of AIH [2]. These autoantibodies are absent in about $10 \%$ of AIH patients [10]. Seronegative AIH was described both in adults and in children with the same demographic, biochemical, and histologic features 


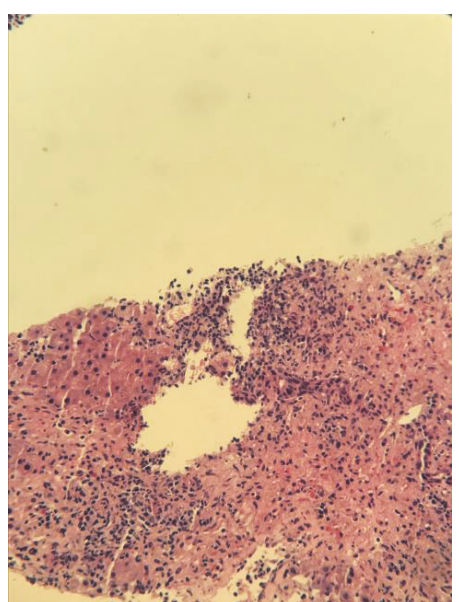

Figure 2: H\&E stain of liver biopsy at low power. Liver Biopsy Pathology Report. Prominent lymphoplasmacytic infiltrate in the portal tracts with marked interface activity and multiple areas of hepatic necrosis. In some foci, plasma cells are particularly prominent.

of classical AIH but negative autoimmune serology [11, 12]. As per the clinical practice guideline for $\mathrm{AIH}$, seronegative patients at diagnosis should be monitored for serologic markers as autoantibody titers may fluctuate and can be expressed later during the course of the disease [2]. There are many studies reporting that some of the patients previously diagnosed with cryptogenic chronic active hepatitis probably had seronegative AIH as they had clinical remission after prednisone therapy and avoided progression to end-stage liver disease [13-15]. Responsiveness to immunosuppressive therapy supports the autoimmune phenomena in all previously reported cases [4]. Although serological markers for $\mathrm{AIH}$ were negative in our patient, a finding based on liver biopsy, rapid improvements of transaminases and IgG level were highly suggesting seronegative $\mathrm{AIH}$ on chronic $\mathrm{HBV}$ infection.

We do not know for sure whether chronic HBV infection was the trigger factor for the development of AIH in our case. More research would require understanding the complicated pathophysiology of this rare viral-induced autoimmune disease.

\section{Conflicts of Interest}

The authors declare that there are no conflicts of interest regarding the publication of this paper.

\section{References}

[1] Y. Shoenfeld, N. Agmon-Levin, and N. R. Rose, Infection and Autoimmunity, 2018, https://books.google.com/books?id= hwzU7K7U4OgC\&amp;pg=PA221\&amp;lpg=PA221\&amp;dq= Elsevier+Viral+Infection+and+Autoimmune+Hepatitis+-+Sandro+Vento+and+Francesca+Cainelli\&amp;source=bl\&amp;ots =pgjMZTIcm9\&amp;sig=c8YyeUxoxXDgf9VMY37M5aMeQnI \&amp;hl=en\&amp;sa=X\&amp;ved=0ahUKEwjs8cToldzXAh WhkOAKH.
[2] European Association for the Study of the Liver, "EASL clinical practice guidelines: autoimmune hepatitis," Journal of Hepatology, vol. 63, no. 4, pp. 971-1004, 2015.

[3] T. Laskus and J. Slusarczyk, "Autoimmune chronic active hepatitis developing after acute type B hepatitis," Digestive Diseases and Sciences, vol. 34, no. 8, pp. 1294-1297, 1989.

[4] C. Murakami, K. Hino, M. Okazaki et al., "Hepatitis B virus carrier status linked to autoimmune hepatitis," Internal Medicine, vol. 35 , no. 6, pp. 468-471, 1996.

[5] H. Bécheur, D. Valla, M. A. Loriot, A. Attar, F. Bloch, and J. P. Petite, "Concurrent emergence of hepatitis B e antigen-negative hepatitis B virus variant and autoimmune hepatitis cured by adenine arabinoside monophosphate," Digestive Diseases and Sciences, vol. 43, no. 11, pp. 2479-2482, 1998.

[6] A. J. Czaja, H. A. Carpenter, P. J. Santrach, S. Breanndan Moore, H. F. Taswell, and H. A. Homburger, "Evidence against hepatitis viruses as important causes of severe autoimmune hepatitis in the United States," Journal of Hepatology, vol. 18, no. 3, pp. 342352, 1993

[7] M. Pawlowska and W. Halota, "Acute liver failure caused by concurrent autoimmune hepatitis and hepatitis B in a 16-year old girl," World Journal of Hepatology, vol. 2, no. 10, pp. 392-394, 2010.

[8] R. Maya, M. E. Gershwin, and Y. Shoenfeld, "Hepatitis B virus (HBV) and autoimmune disease," Clinical Reviews in Allergy \& Immunology, vol. 34, no. 1, pp. 85-102, 2008.

[9] I. G. McFarlane, "Immunological abnormalities and hepatotropic viral infections," Clinical \& Experimental Immunology, vol. 87, no. 3, pp. 337-339, 1992.

[10] Q. X. Wang, W. J. Jiang, Q. Miao et al., "Clinical and histological features of autoantibody-negative autoimmune hepatitis in Chinese patients: A single center experience," Journal of Digestive Diseases, vol. 14, no. 4, pp. 175-180, 2013.

[11] G. Maggiore, G. Socie, M. Sciveres et al., "Seronegative autoimmune hepatitis in children: Spectrum of disorders," Digestive and Liver Disease, vol. 48, no. 7, pp. 785-791, 2016.

[12] J. M. Sherigar, A. Yavgeniy, D. Guss, N. Ngo, and S. Mohanty, "Seronegative autoimmune hepatitis a clinically challenging difficult diagnosis," Case Reports in Medicine, vol. 2017, Article ID 3516234, pp. 1-3, 2017.

[13] A. J. Czaja, J. E. Hay, and J. Rakela, "Clinical features and prognostic implications of severe corticosteroid-treated cryptogenic chronic active hepatitis," Mayo Clinic Proceedings, vol. 65, no. 1, pp. 23-30, 1990.

[14] D. J. Gassert, H. Garcia, K. Tanaka, and J. F. Reinus, "Corticosteroid-responsive cryptogenic chronic hepatitis: evidence for seronegative autoimmune hepatitis," Digestive Diseases and Sciences, vol. 52, no. 9, pp. 2433-2437, 2007.

[15] S. Heringlake, A. Schütte, P. Flemming, W. Schmiegel, M. P. Manns, and H. L. Tillmann, "Presumed cryptogenic liver disease in Germany: high prevalence of autoantibody-negative autoimmune hepatitis, low prevalence of NASH, no evidence for occult viral etiology," Zeitschrift für Gastroenterologie, vol. 47, no. 5, pp. 417-423, 2009. 


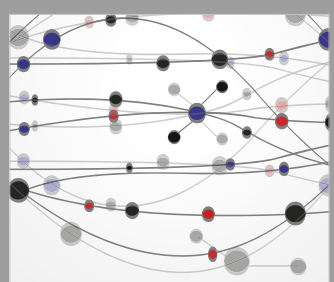

The Scientific World Journal
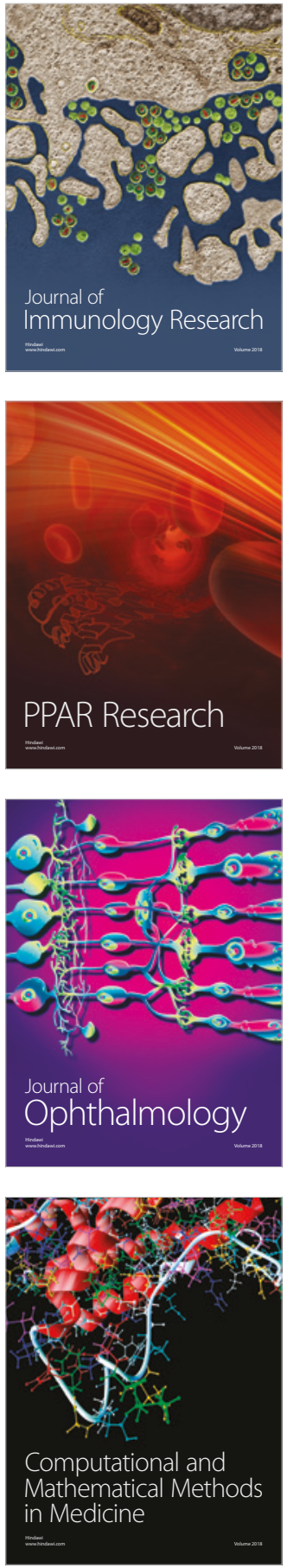

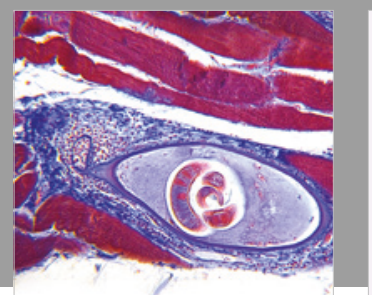

Gastroenterology Research and Practice

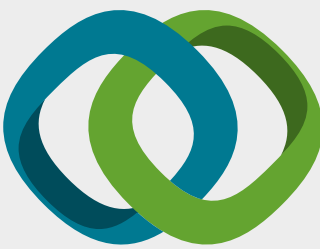

\section{Hindawi}

Submit your manuscripts at

www.hindawi.com
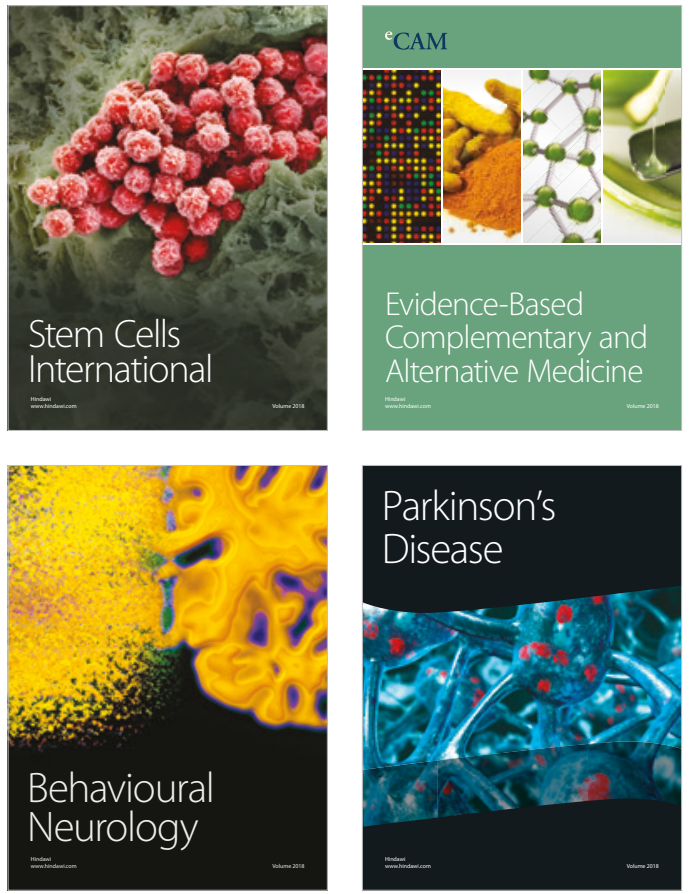

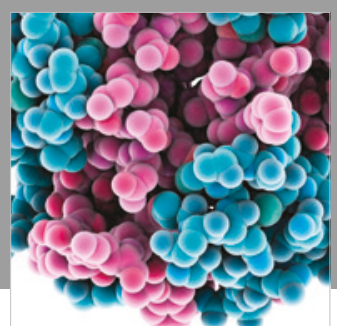

ournal of

Diabetes Research

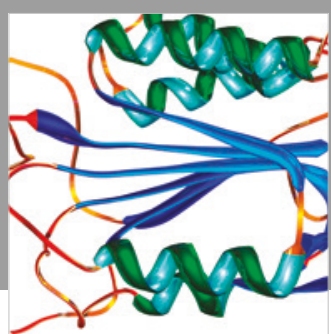

Disease Markers
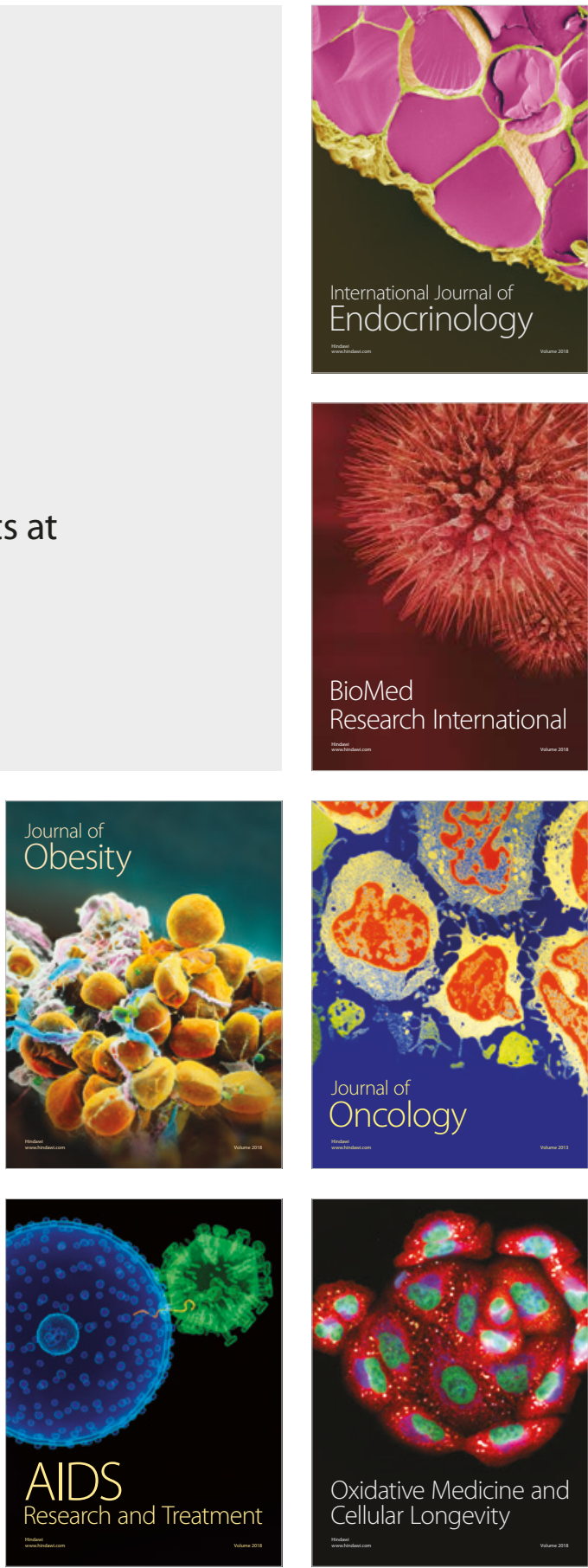